2000s-36

\title{
Conventions and Local Interaction Structures: Experimental Evidence
}

Siegfried K. Berninghaus,

Karl-Martin Ehrhart, Claudia Keser

Série Scientifique

Scientific Series

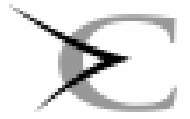

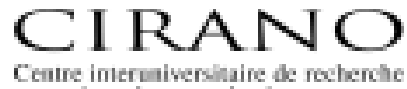

en analyne des organisatices

Montréal

Septembre 2000 


\section{CIRANO}

Le CIRANO est un organisme sans but lucratif constitué en vertu de la Loi des compagnies du Québec. Le financement de son infrastructure et de ses activités de recherche provient des cotisations de ses organisationsmembres, d'une subvention d'infrastructure du ministère de la Recherche, de la Science et de la Technologie, de même que des subventions et mandats obtenus par ses équipes de recherche.

CIRANO is a private non-profit organization incorporated under the Québec Companies Act. Its infrastructure and research activities are funded through fees paid by member organizations, an infrastructure grant from the Ministère de la Recherche, de la Science et de la Technologie, and grants and research mandates obtained by its research teams.

\section{Les organisations-partenaires / The Partner Organizations}

-École des Hautes Études Commerciales

-École Polytechnique

-Université Concordia

-Université de Montréal

-Université du Québec à Montréal

-Université Laval

-Université McGill

-MEQ

-MRST

-Alcan Aluminium Ltée

-AXA Canada

-Banque Nationale du Canada

-Banque Royale du Canada

-Bell Québec

-Bombardier

-Bourse de Montréal

-Développement des ressources humaines Canada (DRHC)

-Fédération des caisses populaires Desjardins de Montréal et de l'Ouest-du-Québec

-Hydro-Québec

-Imasco

-Industrie Canada

-Pratt \& Whitney Canada Inc.

-Raymond Chabot Grant Thornton

-Ville de Montréal

(c) 2000 Siegfried K. Berninghaus, Karl-Martin Ehrhart et Claudia Keser. Tous droits réservés. All rights reserved. Reproduction partielle permise avec citation du document source, incluant la notice ( ).

Short sections may be quoted without explicit permission, provided that full credit, including ( $)$ notice, is given to the source.

Ce document est publié dans l'intention de rendre accessibles les résultats préliminaires de la recherche effectuée au CIRANO, afin de susciter des échanges et des suggestions. Les idées et les opinions émises sont sous l'unique responsabilité des auteurs, et ne représentent pas nécessairement les positions du CIRANO ou de ses partenaires.

This paper presents preliminary research carried out at CIRANO and aims at encouraging discussion and comment. The observations and viewpoints expressed are the sole responsibility of the authors. They do not necessarily represent positions of CIRANO or its partners.

\section{ISSN 1198-8177}




\title{
Conventions and Local Interaction Structures: Experimental Evidence*
}

\author{
Siegfried K. Berninghaus ${ }^{\dagger}$, Karl-Martin Ehrhart $^{\ddagger}$, Claudia Keser ${ }^{\S}$
}

\section{Résumé / Abstract}

Nous présentons une série de jeux de coordination expérimentaux avec un équilibre de Nash qui est dominant par rapport au risque et un autre équilibre qui est dominant par rapport au gain. Nous examinons à quel degré des structures d'interaction locale ont une influence sur les choix de stratégies. Nos observations majeures sont les suivantes: Premièrement, l'interaction locale avec des voisinages autour d'un cercle implique moins de coordination sur l'équilibre qui est dominant par rapport au gain que l'interaction dans des voisinages fermés (voir aussi Keser, Ehrhart et Berninghaus, Economics Letters, 1998). Deuxièmement, quand les joueurs sont disposés en cercle, la taille du voisinage n'a pas d'effet à long terme sur les choix de stratégie par les joueurs. Troisièmement, avec la même taille de voisinage, des joueurs disposés en tore tendent moins que des joueurs disposés en cercle de se coordonner sur l'équilibre qui est dominant par rapport au gain. Cette différence est présente bien que les joueurs reçoivent exactement les mêmes instructions.

We present a set of experimental coordination games with a payoffdominant and a risk-dominant Nash equilibrium. We examine how much local interaction structures affect players' strategy choices. Our three major observations are the following: First, local interaction with open neighborhoods along a circle leads to less coordination on the payoff-dominant equilibrium than interaction in closed neighborhoods (see also Keser, Ehrhart, and Berninghaus, Economics Letters, 1998). Second, when players are allocated around a circle, the neighborhood size has, in the long run, no effect on the players' strategy choices. Third, with the same neighborhood size, players allocated on a lattice tend less than players allocated around a circle to coordinate on the payoffdominant equilibrium. This is true although the players are given exactly the same instructions.

\footnotetext{
* Corresponding Author: Siegfried K. Berninghaus, Universität Karlsruhe, Gebäude 20.21, D-76128 Karlsruhe, Germany. Tel.: +497216083380Ｆax: +497216083491ｅmail: sbe@VWL3.wiwi.uni-karlsruhe.de Financial support by the Deutsche Forschungsgemeinschaft, Sonderforschungsbereich 504 (Project C4) at the University of Mannheim, is gratefully acknoewledged.

$\dagger$ Universität Karlsruhe

† Universität Karlsruhe

$\S$ Universität Karlsruhe and CIRANO
} 
Mots Clés : Sélection des équilibres, structure d'interaction locale, économie expérimentale Keywords: Equilibrium selection, local interaction structures, experimental economics JEL: C72, C90 


\section{Introduction}

Since the seminal work of Schelling (1960), Lewis (1969), Schotter (1981), Jones (1984), and Sudgen (1986) on the evolution of conventions, interest in this field has been growing rapidly. A convention can be defined as a regularity in behavior amongst members of a society in a recurrent situation such that no member of the society alone benefits by deviating from this behavior. In other words, it is a pattern of behavior that is customary, expected, and selfenforcing when several such regularities in behavior are possible. Driving on the right side of the road, for example, is a convention in many countries. In other countries the convention is to drive on the left side. The question which imposes itself is, if there are several potential conventions, which one will actually be chosen in a society? Will indeed everybody choose the same convention or will there be subgroups with different conventions?

Game-theoretically, the choice of conventions problem can be identified by the equilibrium selection problem in so-called pure coordination games (see also Van Huyck, 1997, and the references therein). Pure coordination games are symmetric $n$-player games with multiple symmetric Nash equilibria which are Pareto rankable in their payoffs. In this framework, a convention can be considered as one out of these equilibria.

Equilibrium selection or coordination problems arise in many economic situations. They may emerge at the level of the internal organization of a firm or at the market level, with respect to the input in a shared production process or with respect to demand linkages. Many economic examples are given by Cooper and John (1988) from the perspective of macroeconomics and by Camerer and Knez (1996) from the perspective of organizational decision making.

Unfortunately, game theory provides no general principle which clearly selects one of the equilibria in such coordination games. The best-known equilibrium selection theory is by Harsanyi and Selten (1988). It is based on two selection principles, payoff dominance and risk dominance, which may have opposing implications.

Much of the evidence in the on-going discussion about equilibrium selection in coordination games, in particular the conflict between payoff and risk dominance, comes from experimental economics. Van Huyck, Battalio, and Beil (1990), for example, find that the number of players may affect equilibrium selection. They observe coordination on the least risky but payoff worst equilibrium in large groups while they observe coordination on the payoff best equilibrium in small groups. Battalio, Samuelson and van Huyck (1999) provide experimental evidence that the so called "optimization premium" matters. The optimization 
premium of a strategy roughly formalizes the pecuniary incentive to select a best response to an opponent's strategy. Battalio, Samuelson and van Huyck observe in their experiments that the risk dominant equilibrium is more likely to emerge the larger the optimization premium is.

Coordination on the payoff-dominant equilibrium can be facilitated by various coordination devices, as an auction in which rights to play are traded (van Huyck et al, 1993), a player's choice between playing or an outside option paying him more than the risk dominant equilibrium (Cooper et al, 1992a) or preplay communication where all players send announcements (Cooper et al, 1992b). Berninghaus and Ehrhart (1998) show that the number of rounds during which a group of subjects interacts may influence the subjects' choices. The higher the number of rounds, the more likely is coordination on the payoff-dominant equilibrium. An additional lesson that we can draw from this result is the necessity to examine the equilibrium selection problem in a dynamic rather than a static framework.

To analyze how conventions evolve in a population many models have been presented that apply the theory of evolutionary games (e.g. Kandori, Mailath and Rob, 1993; Young, 1993). In this framework boundedly rational members of a large population interact in coordination games on the basis of pairwise random matching. Under the assumption that players play best reply but deviate from this rule with a small, vanishing probability, we observe convergence to the risk-dominant equilibrium in the long run.

The assumption of pairwise random matching might be an appropriate assumption in a biological context, but in a socioeconomic context it seems less relevant. In some recent work (e.g. Anderlini and Ianni, 1993; Ellison 1993; Blume, 1993; Berninghaus and Schwalbe, 1996) local interaction structures have been considered and many interesting results could be derived. In these models, each member of a population is assumed to be matched with a selected group of population members, called his reference group or neighborhood. Furthermore, these reference groups are supposed to be overlapping such that no group of the population can split off from the rest of the population. As a consequence, each player interacts directly only with a selected group but indirectly with the whole population.

Ellison (1993) has shown that convergence to the risk-dominant equilibrium in the evolutionary learning framework of Kandori, Mailath and Rob (1993) but with local interaction structures speeds up convergence to the risk-dominant equilibrium. Berninghaus and Schwalbe (1996), have analyzed the effects of the neighborhood size and structure on the evolution of conventions in a deterministic automata network. They show that the stability of a risk-dominant equilibrium strongly depends on the neighborhood size. A larger 
neighborhood makes the risk-dominant equilibrium less stable than a smaller neighborhood. This result is derived in so-called one-dimensional local interaction structures where the players are supposed to be allocated around a circle. When the players are allocated on a lattice, and are thus in a two-dimensional interaction structure, more variation in the results can be observed. In contrast to one-dimensional interaction structures where exactly one convention will evolve in the long run, we may find coexistence of conventions on the lattice (see also Anderlini and Ianni, 1993; Goyal and Jansen, 1993; Sudgen, 1993).

In this paper we want to examine whether the theoretical results on equilibrium selection in local interaction structures have their experimental counterparts. In Keser, Ehrhart, and Berninghaus (1998), we observe that it matters whether subjects interact in closed neighborhoods where all players directly interact with each other or in open neighborhoods where players directly interact with their neighbors only and where neighborhoods are overlapping. While choosing the payoff-dominant strategy turned out to be an experimental regularity in equilibrium selection in closed neighborhoods, the riskdominant strategy was chosen more often in open neighborhoods. More precisely, in the experiments we observed that seven of eight groups of the closed neighborhood treatment coordinated within a few repetitions on the payoff-dominant equilibrium. All eight open neighborhood groups, in contrast, ended in the risk-dominant equilibrium, although convergence was rather slow in some groups. In the following, we will put our previous experimental results in a more general framework and, in particular, address the questions of the impact of neighborhood sizes and structures.

In Section 2 we present the specific so-called neighborhood games on which our experiments are based. We have designed them in accordance with the theoretical framework of Berninghaus and Schwalbe (1996). The experimental design is described in Section 3. Section 4 presents the overall results. In Sections 5 we examine the individual behavior of our subjects more closely. In Section 6 we offer an explanation for the observed differences in the outcome of the game where players are allocated around a circle and the game where players are allocated on a lattice. Section 7 concludes the article. 


\section{The coordination games}

The baseline game is a symmetric two-player coordination game, with two strict equilibria in pure strategies. One equilibrium is payoff-dominant while the other is risk-dominant. Based on this game, we construct so-called neighborhood games in which each player plays the baseline game with a single strategy with several other players. According to the payoff function we distinguish between minimum and average games. Furthermore, we consider various interaction structures. An interaction structure determines for a population of players with which other players each player interacts. We consider closed neighborhoods and open neighborhoods with local interaction either around a circle or on a lattice.

\subsection{The two-player coordination game}

The baseline game $G$ is a symmetric normal-form game with two players $i=1,2$. Each player $i$ chooses a strategy $\sigma_{i} \in\{X, Y\}$. The payoff function $H_{i}\left(\sigma_{i}, \sigma_{j}\right)$ is illustrated in Table 1.

Table 1:

The two-player coordination game

\begin{tabular}{c|c|c|} 
& $X$ & $Y$ \\
\hline$X$ & $a, a$ & $b, c$ \\
\hline$Y$ & $c, b$ & $d, d$ \\
\hline
\end{tabular}

$d>a, a>c, d>b, a-c>d-b$

This game has two strict Nash equilibria in pure strategies, $(X, X)$ and $(Y, Y)$. The $(Y, Y)$ equilibrium is payoff-dominant as both players get a higher payoff than in the $(X, X)$ equilibrium. Furthermore, there exists an equilibrium in mixed strategies in which each player chooses $X$ with probability $p^{*}=(d-b) /(a-c+d-b)$. The $(X, X)$-equilibrium satisfies Harsanyi and Selten's (1988) criterion of risk dominance, as $(a-c)>(d-b)$. This implies that $p^{*}<1 / 2$. 


\subsection{Neighborhood games}

From the baseline two-player coordination game $G$, we derive neighborhood games in which each player out of a population of $N(N \geq 2)$ players plays the game $G$ with a single strategy with $n_{i}\left(1 \leq n_{i} \leq N-1\right)$ other players (his neighbors). Let $I$ be the population of players, with $|I|=N<\infty$. Furthermore, let $\left\{N_{i}\right\}_{i \in I}$ be a given interaction (or neighborhood) structure with $\left|N_{i}\right|=n_{i}, N_{i} \subset I, j \in N_{j} \Leftrightarrow i \in N_{j}$, and $i \notin N_{i}$. The interaction structure determines the structure of strategic interdependence between the players in the population. Player i's payoff function $\Pi_{i}\left(\sigma_{i},\left\{\sigma_{j}\right\}_{j \in N_{i}}\right)$ in the neighborhood game is a function of $\left\{H_{i}\left(\sigma_{i}, \sigma_{j}\right)\right\}_{j \in N_{i}}$, the set of payoffs that player i realizes in his $n_{i}$ plays of the game $\mathrm{G}$.

We consider two types of payoff function, a minimum function with

$$
\Pi_{i}(\cdot)=\min \left(\left\{\mathrm{H}_{\mathrm{i}}\left(\sigma_{i}, \sigma_{j}\right)\right\}_{j \in N_{i}}\right)
$$

and an average function with

$$
\Pi_{i}(\cdot)=\frac{1}{n_{i}} \sum_{\mathrm{j} \in \mathrm{N}_{\mathrm{i}}} \mathrm{H}_{\mathrm{i}}\left(\sigma_{i}, \sigma_{j}\right)
$$

To consider equilibria in a neighborhood game we require that each player satisfies the local best reply assumption: each player chooses the strategy which maximizes his payoff $\Pi_{i}(\cdot)$, given the distribution of choices in his neighborhood.

Theorem: In neighborhood games based on game $G$, whatever $N$, the size of the population of players, and whatever the interaction structure $\left\{N_{i}\right\}_{i \in I}$, two equilibria in pure strategies exist: in the (all $X$ )-equilibrium all players of the population choose strategy $X$, while in the (all $Y$ )-equilibrium all players of the population choose strategy $Y$. These equilibria need not be the unique ones; other equilibria might exist. 
The proof is obvious. If in a population all players but player $i$ choose strategy $X$, then all of player $i$ 's neighbors choose strategy $X$ and player $i$ 's best response is to choose strategy $X$. Similarly, if in a population all players but player $i$ choose strategy $Y$, then all of player $i$ 's neighbors choose strategy $Y$ and player $i$ 's best response is to choose strategy $Y$. Depending on the specific interaction structure, there might exist other equilibria which are characterized by the coexistence of both conventions, $X$ and $Y$ (see Figure 2 below for an example). Note that, although the number of equilibria depends on the specific interaction structure and the size of the population, the assumption of complete information about these features is not crucial given our local best reply assumption.

\subsection{Specific neighborhood games}

In our experiments we consider games which are based on the specific baseline two-player coordination game $\mathrm{G}$ that is illustrated in Table $2(a=80, b=60, c=10, d=90)$. Interaction structures are symmetric in the sense that $n_{i}=n$ for all $i \in I$.

\section{Closed neighborhoods:}

In a closed neighborhood each player interacts with each of the other players in the population. Thus, $n=N-1$. We consider populations of $\operatorname{size} N=3$.

Open neighborhoods: Local interaction along a circle:

$N$ players are allocated around a circle. Each player interacts with his $n$ (local) neighbors on the circle, $m$ right and $n-m$ left neighbors. We consider neighborhood sizes of $n=2$ and $n=4$, with $m=n / 2$. For example in case of two neighbors $(n=2)$, a player $i$, with $1<i<N$, has player $i-1$ as his left neighbor, and player $i+1$ as his right neighbor. The left neighbor of player 1 is player $N$, while player 2 is his right neighbor. Similarly, the right neighbor of player $N$ is player 1 , while player $N-1$ is his left neighbor. 
Open neighborhoods: Local interaction on a lattice:

To play a four-neighbors-game $(n=4)$, sixteen players $(N=16)$ are allocated on a lattice. Each player interacts with his four (local) neighbors on the lattice, his left, right, top and bottom neighbor. If the players are allocated as illustrated in Figure 1, player 6 , for example, has player 5 as his left neighbor, player 7 as his right neighbor, player 2 as his top neighbor and player 10 as his bottom neighbor. Player 1 has player 4 as his left neighbor, player 2 as his right neighbor, player 13 as his top neighbor and player 5 as his bottom neighbor. ${ }^{1}$

\begin{tabular}{|c|c|c|c|c|}
\hline & 13 & 14 & 15 & 16 \\
\hline 4 & 1 & 2 & 3 & 4 \\
\hline 8 & 5 & 6 & 7 & 8 \\
\hline 12 & 9 & 10 & 11 & 12 \\
\hline 16 & 13 & 14 & 15 & 16 \\
\hline & 1 & 2 & 3 & 4 \\
\hline
\end{tabular}

Figure 1: $\quad$ Allocation of sixteen players on a lattice

We consider the six different neighborhood games described in Table 3. MIN2GROUP and MIN2CIRCLE are games with two neighbors and a minimum payoff function (minimum games). MIN2GROUP is with closed neighborhoods while MIN2CIRCLE is with local interaction around a circle. Games AVG2GROUP and AVG2CIRCLE differ from games MIN2GROUP and MIN2CIRCLE only in that they are with an average payoff function (average games). Games AVG4CIRCLE and AVG4LATTICE are average games with four neighbors. Both games are with local interaction, along a circle in AVG4CIRCLE and on a lattice in AVG4LATTICE. The number of sessions (last column in Table 3) per treatment was chosen such that they yield us 8 independent observations for each game, allowing us to use relatively conservative nonparametric statistics (Siegel 1956).

\footnotetext{
${ }^{1}$ Note that players at the edges of the lattice have their neighbors at the adverse edges. For example, player 1 has 4 as his left and 13 as his upper neighbor. Such a construction is more properly called a "torus."
} 
Table 2:

The specific baseline two-player coordination game $\mathrm{G}$

\begin{tabular}{c|c|c|} 
& $X$ & $Y$ \\
\hline$X$ & 80,80 & 60,10 \\
\hline$Y$ & 10,60 & 90,90 \\
\hline
\end{tabular}

Table 3:

Six different neighborhood games

\begin{tabular}{cccccc}
\hline \hline game & payoff function & $n$ & interaction structure & $N$ & $\begin{array}{c}\text { \# sessions } \\
\text { (players/session) }\end{array}$ \\
\hline MIN2GROUP & Minimum & 2 & closed & 3 & $2(12)$ \\
MIN2CIRCLE & Minimum & 2 & circle & 8 & $4(16)$ \\
AVG2GROUP & Average & 2 & closed & 3 & $2(12)$ \\
AVG2CIRCLE & Average & 2 & circle & 8 & $4(16)$ \\
AVG4CIRCLE & Average & 4 & circle & 16 & $8(16)$ \\
AVG4LATTICE & Average & 4 & lattice & 16 & $8(16)$ \\
\hline
\end{tabular}

Tables 4 to 6 illustrate the payoff functions for the six neighborhood games: Table 4 for the minimum games with $n=2$ (MIN2GROUP and MIN2CIRCLE), Table 5 for the average games with $n=2$ (AVG2GROUP and AVG2CIRCLE), and Table 6 for the average games with $n=4$ (AVG4CIRCLE and AVG4LATTICE). Note that we based the subjects' instructions about the rules of the game on these payoff tables.

Table 4:

Player $i$ 's payoff in a minimum game with two neighbors

\begin{tabular}{cc|c|c|c|} 
& & \multicolumn{3}{c}{ player $i$ 's neighbors' decisions } \\
& & both $X$ & $\begin{array}{c}\text { one } X \\
\text { one } Y\end{array}$ & both $Y$ \\
\cline { 2 - 5 } player $i$ 's & $X$ & 80 & 60 & 60 \\
decision & $Y$ & 10 & 10 & 90 \\
\cline { 2 - 5 } & & \multicolumn{3}{|c}{}
\end{tabular}


Table 5:

Player $i$ 's payoff in an average game with two neighbors

\begin{tabular}{cc|c|c|c|} 
& & \multicolumn{3}{c}{ player $i$ 's neighbors' decisions } \\
& & both $X$ & $\begin{array}{c}\text { one } X \\
\text { one } Y\end{array}$ & both $Y$ \\
\cline { 2 - 5 } player $i$ 's & $X$ & 80 & 70 & 60 \\
\hline decision & $Y$ & 10 & 50 & 90 \\
\cline { 2 - 5 }
\end{tabular}

Table 6:

Player $i$ 's payoff in an average game with four neighbors

\begin{tabular}{c|c|c|c|c|c|c|} 
& \multicolumn{7}{c}{ player $i$ 's neighbors' decisions } \\
& & All $X$ & $\begin{array}{c}\text { Three } X \\
\text { one } Y\end{array}$ & $\begin{array}{c}\text { two } X \\
\text { two } Y\end{array}$ & $\begin{array}{c}\text { one } X \\
\text { three } Y\end{array}$ & all $Y$ \\
player $i$ 's & $X$ & 80 & 75 & 70 & 65 & 60 \\
\hline decision & $Y$ & 10 & 30 & 50 & 70 & 90 \\
\cline { 2 - 7 }
\end{tabular}

Remark 1: In all games but AVG4LATTICE the (all $X$ )-equilibrium and the (all $Y$ )equilibrium are the only equilibria in pure strategies.

Remark 2: In game AVG4LATTICE additional equilibria in pure strategies exist in which 8 or 12 players choose strategy $\mathrm{Y}$ while the remaining players choose strategy $\mathrm{X}$. Figure 2 presents an example of such an equilibrium configuration.

\begin{tabular}{|c|c|c|c|c|}
\hline & $X$ & $X$ & $Y$ & $Y$ \\
\hline$Y$ & $X$ & $X$ & $Y$ & $Y$ \\
\hline$Y$ & $X$ & $X$ & $Y$ & $Y$ \\
\hline$Y$ & $X$ & $X$ & $Y$ & $Y$ \\
\hline$Y$ & $X$ & $X$ & $Y$ & $Y$ \\
\hline & $X$ & $X$ & $Y$ & $Y$ \\
\hline
\end{tabular}

Figure 2: An equilibrium configuration in game AVG4LATTICE 
It is easy to see that in an equilibrium configuration in AVG4LATTICE each player choosing $Y$ has to have at least three neighbors choosing $Y$. In general, equilibrium configurations of the AVG4LATTICE game can be characterized by the requirement that the $X$-players build "rectangles" in the lattice consisting of at least four players. In particular, when we consider equilibrium configurations consisting of either only rows (columns) of $X$ or $Y$-players this implies that $Y$-rows ( $Y$-columns) have to be situated next to each other. Figure 2 presents such an equilibrium configuration.

We do not argue that the local interaction structures we consider in this paper can be detected in real world societies. In general, we will find mixed interaction structures. At the present stage of knowledge we are still far from capturing real world interaction structures. It is our hope that the simple, stylized local interaction structures analyzed here can be incorporated into a more sophisticated theory of interaction structures. 


\section{Experimental design}

In an experimental session, the respective game is played 20 times by the same population of players and with the same neighborhood structure. In each of the 20 rounds, each player chooses between strategy $X$ and strategy $Y$. A player $i$ 's payoff depends on his own choice and on the choice of his neighbors, i.e., those players with whom he directly interacted.. A neighbor's payoff depends on the choices of the neighbor's own neighbors - of whom one is player $i$.

After each repetition, each player is informed about the distribution of his neighbors' decisions in the round just finished. He is not informed about the individual decisions of his neighbors. Nor is he informed, in case of open neighborhoods, about his neighbors' neighbors' decisions. A player's payoff is determined by the sum of his payoffs in all 20 rounds. Players have complete information about the game in the sense that they know each player's payoff function and that the game ends after 20 rounds. In case of open neighborhoods, they know that their neighbors also interact with other neighbors. They are, however, not explicitly told that they are allocated around a circle or a lattice, and they are not informed about the size $N$ of the circle or the lattice. Note that these informational assumptions on the players' side are not arbitrary but taken from the theoretical models on local interaction that we mentioned in the introduction. In most of these models, players are supposed to adapt their strategies from one round to the next by myopic best response to the distribution of their neighbors' strategies in the previous round.

\section{Organization of the experiments}

We ran the experiments at the University of Karlsruhe. Subjects were students from various disciplines. We continuously recruit students for a pool of potential subjects through notices on bulletin boards around the university campus. Out of this subject pool we randomly selected students for participation in these experiments. The experiments were computerized. Each subject was seated at a computer terminal which was separated from the other subjects' terminals by wooden screens. The subjects received written instructions, which were also read aloud by a research assistant. Before the experiment started, each subject had to answer at his computer terminal a couple of questions with respect to the instructions. Only after all subjects had given the right answers to all questions was the experiment started. No 
communication other than through the decision making was permitted. Subjects could not identify which members of the subject group they actually interacted with.

In all games, the subjects were informed about the payoff function, the number of neighbors, and whether they were interacting in closed or open neighborhoods. They were, however, not informed about the specific type of interaction structure and the size of the population in case of open neighborhoods. They were told that the other players with whom they interacted also interacted with other players. We did not tell the subjects the exact interaction structure, since this might have confused some of them who were not familiar with these concepts. Moreover, in real life games, players often do only know the members of their reference group but do not know how these members themselves are interrelated.

\section{$\underline{\text { Payment }}$}

At the end of an experimental session, the subjects were paid in cash according to their payoffs in the game. The conversion rate was 1 deutsche mark (DM) for 100 game points. The theoretical maximum that could be earned was DM 18 if a subject had always found himself in the (all $Y$ )-equilibrium. The minimum that could be earned was DM 2 if a subject had always chosen the $Y$-strategy in a disequilibrium situation. A subject who always found himself in the (all $X$ )-equilibrium, would have earned DM 16. The average, minimum and maximum payments realized in each of the six games are presented in Table 8. The experimental sessions lasted less than one hour on average.

Table 8:

Average, minimum, and maximum payments

\begin{tabular}{cccc}
\hline \hline Game & Average payment & Minimum payment & Maximum payment \\
\hline MIN2GROUP & 16.32 & 13.20 & 18.00 \\
MIN2CIRCLE & 13.27 & 8.50 & 15.80 \\
AVG2GROUP & 19.90 & 13.20 & 18.00 \\
AVG2CIRCLE & 15.80 & 8.10 & 18.00 \\
AVG4CIRCLE & 15.50 & 12.20 & 18.00 \\
AVG4LATTICE & 14.40 & 5.40 & 17.40 \\
\hline
\end{tabular}




\section{Results}

Table 9 gives an overview over the aggregate results for each of the six games: the percentage of $X$-decisions in the first round and over all 20 rounds, the number of populations that reached at least once an $X$-equilibrium or a $Y$-equilibrium, the average number of rounds that a population stayed in an $X$-equilibrium or a $Y$-equilibrium, the average number of rounds before the first $X$-equilibrium or before the first $Y$-equilibrium was reached.

In the following, we illustrate these results. Specifically, we try to answer three questions regarding the importance of risk dominance and payoff dominance as equilibrium selection criterion:

1) Does local interaction matter?

2) Does the neighborhood size matter?

3) Does the interaction structure matter?

Note, that in this section we use nonparametric test statistics following Siegel (1956), and require significance at the 5 percent level. 
Table 9:

Overview of the results

\begin{tabular}{|c|c|c|c|c|c|c|c|c|}
\hline \multirow[b]{2}{*}{ Game } & \multicolumn{2}{|c|}{ percentage of $X$-decisions } & \multicolumn{2}{|c|}{$\begin{array}{l}\text { number of populations that } \\
\text { reached at least once a }\end{array}$} & \multicolumn{2}{|c|}{ average number of rounds in } & \multicolumn{2}{|c|}{$\begin{array}{l}\text { average number of rounds } \\
\text { before a population reached its } \\
\text { first }\end{array}$} \\
\hline & first round & $\begin{array}{l}\text { All } 20 \\
\text { rounds }\end{array}$ & $X$-equilibrium & $Y$-equilibrium & $X$-equilibrium & $Y$-equilibrium & $X$-equilibrium & $Y$-equilibrium \\
\hline MIN2GROUP & 29.2 & 15.0 & 2 & 7 & 1.7 & 15.5 & 3.0 & 1.7 \\
\hline MIN2CIRCLE & 46.9 & 74.9 & 8 & 1 & 8.1 & 0.4 & 10.9 & 3.0 \\
\hline AVG2CIRCLE & 31.3 & 28.3 & 2 & 5 & 0.9 & 8.9 & 16.0 & 4.4 \\
\hline AVG4CIRCLE & 46.9 & 34.1 & 1 & 4 & 0.1 & 4.6 & 18.0 & 5.3 \\
\hline AVG4LATTICE & 51.2 & 61.1 & 5 & 1 & 4.6 & 1.0 & 11.8 & 11.0 \\
\hline
\end{tabular}




\subsection{Does local interaction matter?}

Our first question concerns the basic issue of theoretical research which shows that local interaction in models of evolutionary strategy adaptation generates different results from global interaction models (e.g. Ellison, 1993). In our experiments, we investigate whether subjects' strategy choices in open neighborhoods differ from subjects' strategy choices in closed neighborhoods with the same number of neighbors. Thus, we compare the percentage of $X$-decisions in closed neighborhoods to the percentage of $X$-decisions in open neighborhoods in games MIN2GROUP and MIN2CIRCLE (see also Keser, Ehrhart, and Berninghaus, 1998) where subjects play the minimum game with two neighbors and in games AVG2GROUP and AVG2CIRCLE where subjects play the average game with two neighbors. Figure 3 shows the percentage of $X$-decisions over all 20 rounds in games MIN2GROUP and MIN2CIRCLE, and Figure 4 shows the percentage of $X$-decisions over all 20 rounds in games AVG2GROUP and AVG2CIRCLE.

In both cases, the minimum game and the average game, the percentage of $X$-decisions in the open neighborhoods is higher than in the closed neighborhoods. Applying a $\chi^{2}$-test, we conclude that in the first round the percentage of $X$-decisions in the open neighborhoods is not significantly different from the percentage of $X$-decisions in the closed neighborhoods. However, over the 20 rounds the percentage of $X$-decisions is in game MIN2CIRCLE significantly higher than in game MIN2GROUP (two-sided U-test based on the independent observations). Similarly, we observe in game AVG2CIRCLE in each round a higher percentage of $X$-decisions than in game AVG2GROUP, although this difference is statistically not significant (two-sided U-test, p-value of 0.194 ). We conclude that in the long run local interaction matters. Risk dominance seems to become with local interaction a more important criterion than without local interaction. The strength of this effect depends, however, on the payoff function of the neighborhood game.

In game MIN2GROUP, 7 of the 8 populations reached a $Y$-equilibrium within very few rounds and then stayed there (with the exception of one population) for the rest of the game. One population quickly reached an $X$-equilibrium and stayed there most of the time. In game MIN2CIRCLE, only one population reached a $Y$-equilibrium in early rounds but ended up, after many rounds of miscoordination, in an X-equilibrium. In total, 4 of the 8 populations ended up in $X$-equilibrium, all 8 populations reached an $X$-equilibrium in several rounds. 
Similarly, in game AVG2GROUP all populations very quickly reached a $Y$ equilibrium, 6 of them stayed there for the rest of the game. One population ended up in an $X$ equilibrium. In game AVG2CIRCLE, 5 populations reached a $Y$-equilibrium in early rounds, four of them stayed there for the rest of the game. Two of the 3 populations that did not reach a $Y$-equilibrium reached an $X$-equilibrium toward the end of the game.

Comparing the games with a minimum payoff function (MIN2GROUP and MIN2CIRCLE) to the games with an average payoff function (AVG2GROUP and AVG2CIRCLE), it is obvious that playing the $Y$-strategy is less risky in the average games than in the minimum games (see also Van Huyck, 1997). Interestingly, games MIN2GROUP and AVG2GROUP with closed neighborhoods lead to very similar results, but games MIN2CIRCLE and AVG2CIRCLE with local interaction around a circle lead to contrasting results. While many populations that play the average game (AVG2CIRCLE) quickly coordinate on the $Y$-equilibrium, populations that play the minimum game (MIN2CIRCLE) less quickly coordinate on the $X$-equilibrium. The percentage of $X$-decisions is significantly higher in MIN2CIRCLE than in AVG2CIRCLE (U-test). Thus, in case of local interaction the payoff function of the neighborhood game plays an important role. It plays a much more important role than in case of closed neighborhoods. In other words, the experimental results are much more sensitive to the payoff function in case of open neighborhoods than in case of closed neighborhoods.

\subsection{Does the neighborhood size matter?}

For closed neighborhoods, we know from Van Huyck, Battalio, and Beil (1990) that the number of players matters. They observed coordination on the payoff-dominant equilibrium in small groups but coordination on the less risky equilibrium in large groups.

In local interaction models adverse theoretical results have been derived by Boyer and Orleans (1992), and Berninghaus and Schwalbe (1996). Large neighborhoods increase the chance of coordination on the payoff-dominant equilibrium. More precisely, one can show in a theoretical model of strategy adaptation via (local) best reply that a payoff-dominant equilibrium state in the AVG2CIRCLE game can be destroyed immediately if at least one player deviates from the payoff-dominant strategy, since both neighbors of the deviating player have the risk-dominant strategy as best reply. This will not happen if one player in 
AVG4CIRCLE deviates from the payoff-dominant equilibrium. This theoretical observation is not adequately repesented in our experimental results.

We compare open neighborhoods along a circle with two neighbors (AVG2CIRCLE) and with four neighbors (AVG4CIRCLE). Figure 5 shows the percentage of $X$-decisions over all 20 rounds in both games. In the first round, the percentage of $X$-decisions in game AVG4CIRCLE is significantly higher than in game AVG2CIRCLE ( $\chi^{2}$-test). After few rounds the differences between the two games disappear. Over all 20 rounds the percentage of $X$ decisions is not significantly different in the two games (U-test). Thus, we have no evidence that the neighborhood size matters when we have local interaction around a circle.

\subsection{Does the interaction structure matter?}

For open neighborhoods with four neighbors, we compare the circle (AVG4CIRCLE) and the lattice structure (AVG4LATTICE). In both games, subjects were given exactly the same instructions which contained information about the number of neighbors but not about the specific type of interaction structure. Figure 6 shows the percentage of $X$-decisions over all 20 rounds in both games.

In all rounds, we observe in game AVG4LATTICE a higher percentage of $X$-decisions than in game AVG4CIRCLE. In the first round, the small difference is statistically not significant $\left(\chi^{2}\right.$-test). However, we observe a significant difference over all 20 rounds (twosided U-test). We conclude that, everything else being equal, it matters whether players are allocated around a circle or on a lattice.

In game AVG4CIRCLE, 4 populations reached a $Y$-equilibrium, and 1 population reached an $X$-equilibrium at the very end of the game. In game AVG4LATTICE, only one population reached a $Y$-equilibrium, but 5 populations reached an $X$-equilibrium. Three of the 5 populations that reached an $X$-equilibrium stayed there until the end of the game. No population ever reached an equilibrium in which some players choose $X$ and others choose $Y$.

From theoretical reasoning in Berninghaus and Schwalbe (1996) we know that the dynamics of strategy adaptation is different in both types of neighborhood structure, circle and lattice, as they differ in the overlapping of neighborhoods. Around the circle, they expect only one convention to emerge. Depending on the starting strategy configuration, either all players choose the risk-dominant strategy or all players choose the payoff-dominant strategy after a 
finite number of rounds. On the lattice, however, several subcultures may play different conventions in a dynamically stable state. That is, the population of players may end up in strategy configurations which display much more variety than populations on the circle. One can observe equilibrium configurations in which even players in the same neighborhood select different strategies. ${ }^{2}$ Obviously, this cannot happen in a circle structure. It is remarkable that in our experimental results we observe significant differences between the circle and the lattice structure. These differences are not exactly in the way predicted by Berninghaus and Schwalbe (1996) but they indicate that both structures lead to different dynamics and thus to the selection of different conventions.

\subsection{Equilibrium situations}

Columns 6 and 7 of Table 9 show how many rounds a population spends on average in an $X$ and a $Y$-equilibrium in each game. In closed neighborhood games (MIN2GROUP and AVG2GROUP), most populations almost immediately coordinate on a $Y$-equilibrium and then stay there. Thus, on average, populations spend 16 rounds in a $Y$-equilibrium. In local interaction games with two neighbors (MIN2CIRCLE and AVG2CIRCLE) populations reach an equilibrium in almost one half of all rounds, an $X$-equilibrium in MIN2CIRCLE and a $Y$ equilibrium in AVG2CIRCLE. In local interaction games with four neighbors (AVG4CIRCLE and AVG4LATTICE) populations reach an equilibrium in only about one quarter of all rounds, a $Y$-equilibrium in AVG4CIRCLE and an $X$-equilibrium in AVG4LATTICE.

Columns 8 and 9 of Table 9 reveal the average number of rounds that a population in each game needed before an $X$-equilibrium and before a $Y$-equilibrium was reached for the first time. We observe that, over all games, a $Y$-equilibrium is reached faster than an $X$ equilibrium (two-sided U-test based on the independent populations that reached an equilibrium).

\footnotetext{
${ }^{2}$ For details we refer the reader to our explanations in Remark 2 (section 2).
} 


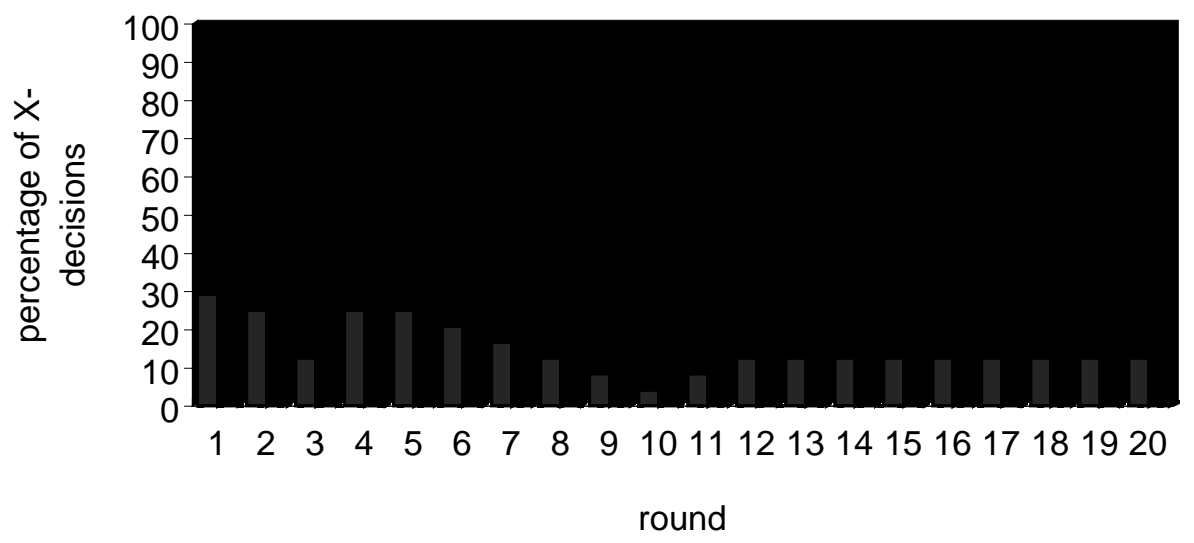

a MIN2GROUP $\square$ MIN2CIRCLE

Figure 3: $\quad$ Percentage of $X$-decisions in games I and II

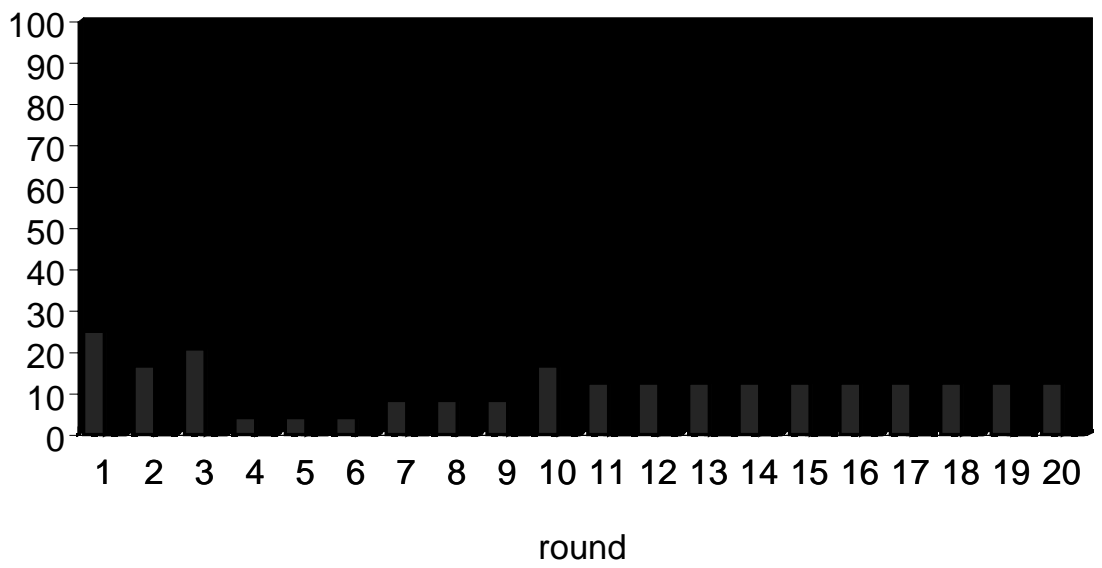

口AVG2GROUP $\square$ AVG2CIRCLE

Figure 4: $\quad$ Percentage of $X$-decisions in games III and IV

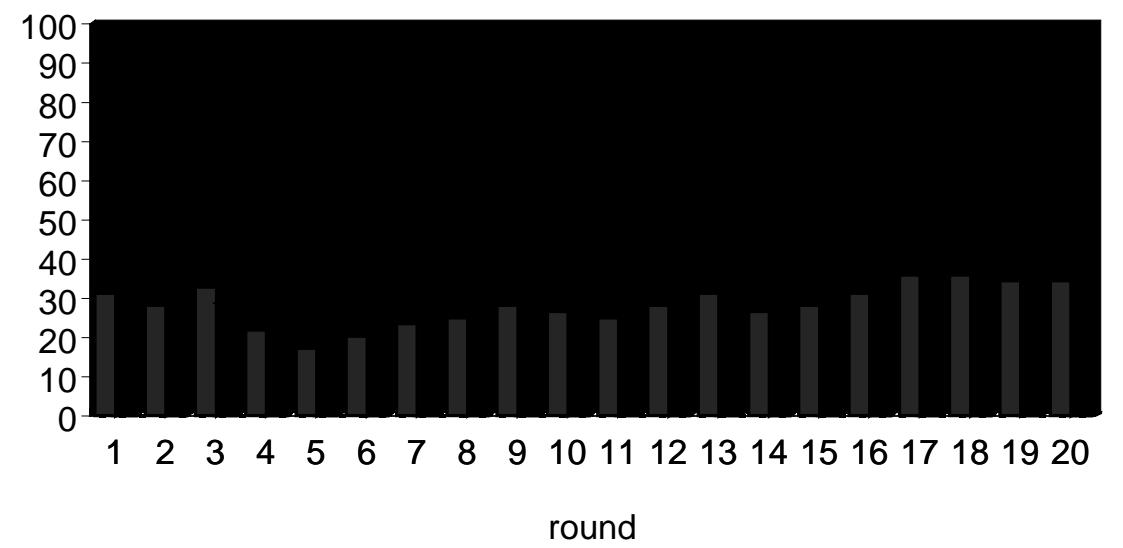

$\square$ AVG2CIRCLE $\square$ AVG4CIRCLE

Figure 5: $\quad$ Percentage of $X$-decisions in games IV and V 


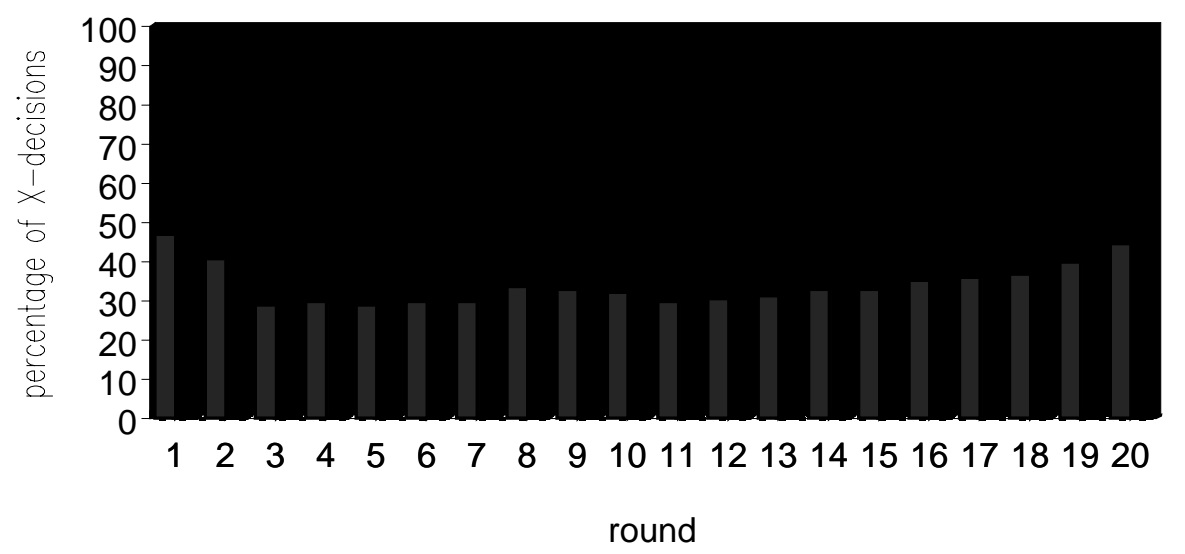

\section{口AVG4CIRCLE 口AVG4LATTICE}

Figure 6: $\quad$ Percentage of $X$-decisions in games I and II 


\section{Individual behavior}

In order to explain the observed differences in equilibrium selection, we investigate subjects' individual decisions.

\subsection{Myopic local best reply}

Berninghaus and Schwalbe (1996) present a local interaction model with automata networks and deterministic strategy adaptation rules. As in most theoretical models of local interaction, they assume local best reply to the previous round strategy distribution. An alternative assumption could be the imitation of the most successful neighbor strategy. This, however, requires much more information on the players' side, in particular information about the payoffs of their neighbors' strategies (see, for example Anderlini and Ianni, 1993).

Note that there exists a large literature on learning models showing that pure (myopic) best reply fares poorly compared to belief reinforcement or hybrid models. Belief learning is examined, for example, by Boylan and El-Gamal (1992), Crawford (1995), and Cheung and Friedman (1997). Bush and Mosteller (1955) and Cross (1983) were the first to present models of reinforcement learning. Hybrid models with reinforcement are presented and confronted with experimental data by Camerer and Ho (1999) and Stahl (1996). It would be interesting to confront some of the learning models with our experimental data. However, this would be beyond the scope of this paper.

Assuming that subjects react to their neighbors' decisions in the previous round, we investigate in how far the observed reactions satisfy the local best reply assumption. In case of two neighbors, following the best reply assumption, a player should react with $X$ if at least one of the neighbors chose $X$. In case of four neighbors, a player should react with $X$ if at least two neighbors chose $X$.

Table 10 shows that in all games subjects have a significant tendency to play best reply to the distribution of their neighbors' decisions in the previous round in all cases except the one that half of the neighbors chose $X$ and the other half chose $Y$. In that case without majority for any of the strategies, subjects' behavior in the six games differs. In the closed neighborhood games MIN2GROUP and AVG2GROUP, subjects significantly tend to play $Y$ although $X$ would be best reply when one of the neighbors chose $X$ while the other chose $Y$. In 
game AVG2CIRCLE with the average payoff function and local interaction around a circle, some subjects react with $Y$ and some with $X$. However, in game MIN2CIRCLE with the minimum payoff function subjects significantly tend to choose $X$ and thus to play best reply. With a neighborhood size of four, we observe the subjects who interact on a lattice tend to play $X$ and thus best reply in case that two neighbors chose $X$ while the other two chose $Y$. When subjects are allocated on a circle, however, we observe no significant tendency to play $X$ in that case.

Table 10:

Percentage of $X$-decisions depending on the frequency of the neighbors' $X$-decisions in the previous round

\begin{tabular}{cccccc}
\hline \hline & \multicolumn{5}{c}{ percentage of $X$-decisions given that the number of neighbors who chose $X$} \\
in the previous round was \\
Game & 0 & 1 & 2 & 3 & 4 \\
\hline MIN2GROUP & $3.0^{*}$ & $28.9 \bullet$ & $86.0^{*}$ & - & - \\
MIN2CIRCLE & $11.6^{*}$ & $64.2^{*}$ & $95.6^{*}$ & - & - \\
AVG2GROUP & $2.1^{*}$ & $30.0^{*}$ & $91.4^{*}$ & - & - \\
AVG2CIRCLE & $4.4^{*}$ & 46.7 & $89.4^{*}$ & - & - \\
AVG4CIRCLE & $2.2^{*}$ & $8.6^{*}$ & 52.8 & $87.9^{*}$ & $97.4^{*}$ \\
AVG4LATTICE & $4.9^{*}$ & $20.7^{*}$ & $57.7^{*}$ & $80.0^{*}$ & $97.8^{*}$ \\
\hline
\end{tabular}

* $\quad$ Significant tendency to play best reply (two-sided Binomial-test)

- $\quad$ Significant tendency not to play best reply (two-sided Binomial-test)

The tendency to play $Y$ although $X$ would be best reply if half of the neighbors chose $X$ and the other half chose $Y$ might be attributed to optimism about achieving the payoff better equilibrium: subjects tend to be more optimistic when they are in a closed neighborhood than in an open neighborhood. There are other interpretations of the observed deviation from best reply behavior however. Subjects might aim at achieving the payoff better equilibrium in a repeated game. As they try to maximize their total payoff, subjects are the more willing to choose $Y$ the more rounds are left to play. Another interpretation is that subjects use Bayesian belief learning with a prior on $Y$, which gradually decays over time as less than expected choices on $Y$ are observed. According to the two latter interpretations, subjects' response behavior would converge to best reply in later rounds. Therefore, we compare the response 
behavior in the first ten rounds (round 1-10) to the response behavior in the second ten rounds (round $11-20) .^{3}$

The results presented in Table 11 give support to the convergence to best reply behavior. In the first ten rounds subjects significantly tend to play best reply in game MIN2CIRCLE only, while in three other games (MIN2GROUP, AVG2GROUP, AVG2CIRCLE) subjects show a significant tendency not to play best reply. However, in the second ten rounds in four games (MIN2CIRCLE, AVG2CIRCLE, AVG4CIRCLE, AVG4LATTICE) subjects significantly tend to play best reply, while there is no game in which subjects show a significant tendency not to play best reply. We conclude that subjects' response behavior converges to best reply behavior in later rounds.

Table 11:

Percentage of $X$-decisions where half of the neighbors chose $X$ and the other half chose $Y$ in the previous round ${ }^{4}$

\begin{tabular}{clll}
\hline \hline & & \multicolumn{3}{c}{ Round } \\
Game & $1-10$ & $11-20$ & $1-20$ \\
\hline MIN2GROUP & $28.1 \bullet$ & 33.3 & $28.9 \bullet$ \\
MIN2CIRCLE & $60.4^{*}$ & $74.4^{*}$ & $64.2^{*}$ \\
AVG2GROUP & $31.6 \bullet$ & 0.0 & $30.0 \bullet$ \\
AVG2CIRCLE & $40.1 \bullet$ & $59.8^{*}$ & 46.7 \\
AVG4CIRCLE & 48.2 & $60.4^{*}$ & 52.8 \\
AVG4LATTICE & 54.9 & $64.4^{*}$ & $57.7^{*}$ \\
\hline
\end{tabular}

* $\quad$ Significant tendency to play best reply (two-sided Binomial-test)

- $\quad$ Significant tendency not to play best reply (two-sided Binomial-test)

\footnotetext{
${ }^{3}$ We are grateful to an anonymous referee who encouraged us to carry out this investigation.

${ }^{4}$ In the second ten rounds the situation that one neighbor chose $X$ and the other chose $Y$ occurred only 6 times in game MIN2GROUP and only twice in game AVG2GROUP. This is the reason why these two games do not show a significant result.
} 


\section{$5.2 \quad$ Lock-in}

We now additionally take the subject's own previous decision into consideration. Table 12 shows the frequencies of $X$-decisions depending on the distribution of the neighbors' decisions in the previous round and on the player's own previous decision. Whatever the distribution of neighbors' decisions, the frequencies of $X$-decisions are somewhat higher when the subject himself chose $X$ in the previous round than when he chose $Y$. This supports the lock-in hypothesis by Blume (1993). One interpretation for lock-in could be heterogeneity in the subjects' propensities to play certain strategies, which could be due to differences in individual beliefs. ${ }^{5}$ Another interpretation is given by the concept of inertia. A player who chooses a specific strategy has a tendency to stay with this strategy for some time.

\section{Table 12:}

Percentage of $X$-decisions depending on the frequency of the neighbors' $X$-decisions in the previous round and a player's own previous decision.

\begin{tabular}{ccccccc}
\hline \hline & & \multicolumn{5}{c}{ Percentage of $X$-decisions given that the number of } \\
& game & 0 & 1 & 2 & 3 & 4 \\
\hline \multirow{5}{*}{ Player's own } & MIN2GROUP & 50.0 & 50.0 & 93.3 & - & - \\
choice was $X$ & MIN2CIRCLE & 41.7 & 86.7 & 98.2 & - & - \\
& AVG2GROUP & 40.0 & 70.0 & 100.0 & - & - \\
& AVG2CIRCLE & 49.0 & 82.1 & 97.8 & - & - \\
& AVG4CIRCLE & 34.1 & 26.6 & 75.6 & 94.6 & 98.2 \\
& AVG4LATTICE & 34.2 & 45.6 & 80.8 & 91.6 & 99.6 \\
\hline \multirow{5}{*}{ Player's own } & MIN2GROUP & 1.1 & 21.4 & 20.0 & - & - \\
choice was $Y$ & AVG2GROUP & 0.5 & 16.7 & 40.0 & - & - \\
& AVG2CIRCLE & 1.1 & 19.6 & 45.7 & - & - \\
& AVG4CIRCLE & 0.9 & 4.6 & 33.3 & 62.3 & 76.9 \\
& AVG4CIRCLE & 2.5 & 34.5 & 66.1 & - & 62.8 \\
\hline
\end{tabular}

\footnotetext{
${ }^{5}$ We thank an anonymous referee for this interpretation.
} 


\subsection{A logit statistical model}

We summarize the observed tendency to play local best reply combined with a lock-in effect in a logit statistical model of individual decision-making. The model is based on the assumption of local best reply to the observed distribution of one's neighbors' choices in the previous round and additionally takes the player's own previous choice into consideration. Although we can observe that the subjects' average response behavior changes slightly in the course of time, for the sake of simplicity we consider one model for all rounds.

Let $\pi$ denote the probability for choosing strategy $X$, and $1-\pi$ the probability for choosing strategy $Y$. The probability for choosing $X$ is given by

$$
\pi=\frac{1}{1+\exp \left(-\mathbf{x}^{\prime} \boldsymbol{B}\right)}
$$

where $\mathbf{x}$ denotes the vector of explanatory variables and $\beta$ the vector of coefficients. Our model can be written as

$$
\ln \frac{\pi}{1-\pi}=\mathbf{x}^{\prime} \boldsymbol{B}=\beta_{0}+\beta_{1} x_{1}+\beta_{2} x_{2},
$$

where $x_{1}$ is the number of neighbors who chose $X$ in the previous round, and $x_{2}$ is a variable with value 1 if the player's own choice was $X$ in the previous round and with value 0 if it was $Y$.

The maximum likelihood estimates of all coefficients are presented in Table 13. The goodness of fit -test shows significance and the estimates of $\beta_{1}$ and $\beta_{2}$ are significantly positive in all games. We conclude that the probability for choosing $X$ increases both with the number of neighbors having chosen $X$ in the previous round as well as with the player's own choice of $X$ in the previous round. 
Table 13:

Results of the logit regressions ${ }^{6}$

\begin{tabular}{cccccc}
\hline \hline Game & $\mathrm{R}$ & $\begin{array}{c}\mathrm{DF} \\
\text { F-Value }\end{array}$ & $\begin{array}{c}\hat{\beta} \\
(\mathrm{t}-\mathrm{v} \text {-value })\end{array}$ & $\begin{array}{c}\hat{\beta}_{1} \\
\text { (t-value) }\end{array}$ & $\begin{array}{c}\hat{\beta}_{2} \\
(\mathrm{t}-\mathrm{v} \text {-value }\end{array}$ \\
\hline MIN2GROUP & 0.807 & 453 & -3.43 & 1.25 & 3.10 \\
& & 423.7 & $(-12.5)$ & $(7.6)$ & $(10.8)$ \\
\hline MIN2CIRCLE & 0.764 & 1213 & -2.69 & 1.87 & 2.57 \\
& & 848.3 & $(-14.7)$ & $(14.1)$ & $(15.8)$ \\
\hline AVG2GROUP & 0.843 & 453 & -3.88 & 1.83 & 3.36 \\
& & 554.1 & $(-12.4)$ & $(9.2)$ & $(10.8)$ \\
\hline AVG2CIRCLE & 0.843 & 1213 & -3.43 & 1.71 & 3.35 \\
& & 1486.7 & $(-18.0)$ & $(14.2)$ & $(18.3)$ \\
\hline AVG4CIRCLE & 0.846 & 2429 & -4.06 & 1.59 & 1.92 \\
& & 3058.8 & $(-23.8)$ & $(20.9)$ & $(18.0)$ \\
\hline AVG4LATTICE & 0.795 & 2429 & -3.14 & 1.11 & 2.16 \\
& & 2083.2 & $(-22.8)$ & $(20.7)$ & $(20.8)$ \\
\hline
\end{tabular}

R: $\quad$ Multiple correlation coefficient

DF: $\quad$ Degrees of freedom

F-Value: $\quad$ Value of the F-statistic of the goodness of fit test

$\hat{\beta}_{k}: \quad$ Estimate of coefficient $\beta_{k}$

t-value: $\quad$ Value of the $\mathrm{t}$-statistic

${ }^{6}$ The statistical analysis was computed with SigmaStat 2.03 . 


\section{Comparison between circle and lattice}

Our statistical analysis of individual behavior so far offers no explanation of why we observe significantly more $X$-decisions in game AVG4LATTICE than in game AVG4CIRCLE. This difference is particularly interesting given that subjects had exactly the same instructions in both games. They were not informed about the actual structure of interaction; they only knew that they had four neighbors who also interacted with others.

If the observed difference in the outcome of the two games is not just a type I error, then it can only be caused by the interaction structure per se. An additional difference between AVG4CIRCE and AVG4LATTICE is that we observe a significantly higher frequency of individual decision changes in AVG4LATTICE (14.1 percent) than in AVG4CIRCLE (10.9 percent). Can such a difference be caused by the different interaction structures? To examine this question let us run simulations. Consider a simple individual decision rule depending on the number of neighbors who chose $X$ in the previous round. The probabilities for playing $X$ are based on the observed frequencies as presented in Table 10: In order to investigate the dynamics we choose values close to the arithmetic means of the frequencies observed in the two games such that the expected frequency of $X$-decisions is 50 percent (given an initial probability of 50 percent). The probabilities and the simulation results are presented in Table 14. 
Table 14:

Conditions and results of the simulations

Conditions

\begin{tabular}{|c|c|c|c|c|c|c|c|}
\hline Games & \multicolumn{7}{|c|}{ AVG4CIRCLE and AVG4LATTICE } \\
\hline \multirow[t]{2}{*}{ Decision rule } & $\begin{array}{l}\text { Numbe } \\
X \text { in pre }\end{array}$ & $\begin{array}{l}\text { ghbors choosing } \\
\text { ound }\end{array}$ & 0 & 1 & 2 & 3 & 4 \\
\hline & Probabi & $X$ in percent & 3 & 15 & 50 & 85 & 97 \\
\hline Initial decision & \multicolumn{7}{|c|}{ Probability for $X$ in the first round $=50 \%$} \\
\hline Number of simulations & \multicolumn{7}{|c|}{ One million 20-round simulations with each game } \\
\hline \multicolumn{8}{|l|}{ Results } \\
\hline & \multicolumn{3}{|c|}{ AVG4CIRCLE } & \multicolumn{4}{|c|}{ AVG4LATTICE } \\
\hline \multicolumn{2}{|l|}{ Percentage of $X$-decisions } & $50.0 \%$ & & \multicolumn{4}{|c|}{$50.0 \%$} \\
\hline \multicolumn{2}{|c|}{ Frequency of decision changes } & $26.8 \%$ & & \multicolumn{4}{|c|}{$49.9 \%$} \\
\hline \multicolumn{2}{|c|}{$\begin{array}{l}\text { Frequency of changes in the } \\
\text { distribution of neighbors' decisions }\end{array}$} & $48.0 \%$ & & \multicolumn{4}{|c|}{$74.1 \%$} \\
\hline
\end{tabular}

In the simulations we observe, as in the experiment, a higher frequency of decision changes in AVG4LATTICE (49.9 percent) than in AVG4CIRCLE (26.8 percent). These values are higher than those observed in the experiment, because for the sake of simplicity we have not incorporated the observed lock-in effect into the decision rule used in the simulations.

The simulation reveals the impact of the interaction structure on the frequency of decision changes. Due to the specific decision rule, the simulation cannot reproduce a difference in the percentage of $X$-decisions. How can we explain the observed differences in frequencies of $X$-decisions in the experiment? Are subjects the more likely to choose the less risky decision $X$ the more decision changes they have observed? To test this hypothesis, let us extend our logit statistical model by a variable which captures the frequency of observed changes in one's neighborhood:

$$
\ln \frac{\pi}{1-\pi}=\mathbf{x}^{\prime} \boldsymbol{B}=\beta_{0}+\beta_{1} x_{1}+\beta_{2} x_{2}+\beta_{3} x_{3},
$$

where $x_{1}$ is the number of neighbors who chose $X$ in the previous round, $x_{2}$ is a variable with value 1 if the player's own choice was $X$ in the previous round and with value 0 if it was $Y$, 
and $x_{3}$ is the average frequency of observed changes in the distribution of the neighbors' choices over all previous rounds. Let $x_{3, t}$ denote the realization of $x_{3}$ in round $t$ and $x_{1, t}$ the number of neighbors who choose $X$ in round $t$. The variable $x_{3, t}$ is calculated for $t \geq 2$ as

$$
\begin{aligned}
& x_{3, t}=\frac{1}{t-1} \sum_{s=2}^{t} z_{s}, \\
& z_{s}=\left\{\begin{array}{l}
0: x_{1, s}=x_{1, s-1} \\
1: \text { otherwise }
\end{array}\right.
\end{aligned}
$$

The estimates of $\beta_{1}, \beta_{2}$, and $\beta_{3}$ are significantly positive in games AVG4CIRCLE and AVG4LATTICE (see Table 15). We conclude from the significantly positive estimate of $\beta_{3}$ in both games that subjects tend to choose the less risky $X$ rather than the more risky $Y$ if they have observed numerous of changes in their neighbors' choices in the past.

These results allow us to explain the higher percentage of $X$-decisions on the lattice than around the circle. In game AVG4LATTICE, where subjects are allocated on a lattice, we observe more individual decision changes than in game AVG4CIRCLE, where subjects are allocated around a circle which, as the simulations show, this is a result of by the different interaction structures. This difference, together with the observation that the subjects tend to react to changes in their neighbors' choices by choosing $X$, gives an explanation for the higher frequency of $X$-decisions on the lattice than around the circle.

Table 15:

Results of the extended logit regressions

\begin{tabular}{ccccccc}
\hline \hline Game & \multirow{2}{*}{$\begin{array}{c}\mathrm{DF} \\
\text { F-Value }\end{array}$} & $\begin{array}{c}\hat{\beta}_{0} \\
(\mathrm{t}-\mathrm{value})\end{array}$ & $\begin{array}{c}\hat{\beta}_{1} \\
(\mathrm{t}-\mathrm{value})\end{array}$ & $\begin{array}{c}\hat{\beta}_{2} \\
\text { (t-value) }\end{array}$ & $\begin{array}{c}\hat{\beta}_{3} \\
\text { (t-value) }\end{array}$ \\
\hline AVG4CIRCLE & \multirow{2}{*}{0.847} & 2428 & -4.42 & 1.62 & 1.98 & 0.78 \\
& & 2053.2 & $(-21.2)$ & $(20.5)$ & $(18.0)$ & $(3.5)$ \\
\hline AVG4LATTICE & \multirow{2}{*}{0.796} & 2428 & -3.43 & 1.11 & 2.17 & 0.65 \\
& & 1397.7 & $(-19.9)$ & $(20.6)$ & $(20.8)$ & $(3.3)$ \\
\hline
\end{tabular}

R: $\quad$ Multiple correlation coefficient

DF: $\quad$ Degrees of freedom

F-Value: $\quad$ Value of the F-statistic of the goodness of fit test

$\hat{\beta}_{k}: \quad \quad$ Estimate of coefficient $\beta_{k}$

t-value: $\quad$ Value of the $\mathrm{t}$-statistic 


\section{Conclusion}

We observe more coordination on the payoff-dominant equilibrium in games with closed neighborhoods than in games with open neighborhoods. Furthermore, riskiness of the payoffdominant equilibrium plays a stronger role in open neighborhoods than in closed neighborhoods. In open neighborhoods of a given size, we see more cooperation on the payoff-dominant equilibrium when there is more overlapping (i.e., around a circle, where each player with each of his neighbors has another neighbor in common) than when there is less overlapping of neighbors (i.e., on a lattice where none of a player's neighbors has any neighbor out of the same neighborhood). The size of the neighborhood around a circle seems not to be of importance. Interestingly, whatever the neighborhood structure, a $Y$-equilibrium is reached faster than an $X$-equilibrium.

Individual behavior depends on the distribution of neighbors' choices in the previous round, one's own previous choice, and the average frequency of observed changes in the distribution of neighbors' choices in all previous rounds. The effect of the average frequency of observed changes on the individual strategy choice provides a satisfactory interpretation of our results for games AVG4CIRCLE and AVG4LATTICE. Since we observe many more strategy changes on the lattice than around the circle, the probability of selecting the less risky strategy should, according to the results of our logit regression, be higher on the lattice than around the circle. This is exactly what we observe in the experiments. Note that, whether circle or lattice structure, the individual decisions rules appear to be similar. As can be seen in simulations, the observed differences between AVG4CIRCLE and AVG4LATTICE are to a large extent caused by the interaction structure per se.

We intend to investigate three further questions in our future work. First, it would be important to let subjects play more than 20 rounds. This would be particularly interesting for the games with a neighborhood size of four players. In these games, the 20 rounds appeared in most populations not to be sufficient for stability. We know from the experimental results by Berninghaus and Ehrhart (1998) that the time horizon of play has a significant influence on players' strategy choice in coordination games. The longer the time horizon, the more likely is coordination on the payoff-dominant equilibrium. Second, for economic applications it would be more realistic to allow communication between neighbors. Will communication lead to coordination on the payoff-dominant equilibrium in all games? This problem has been investigated by Cooper et al. (1992b) for coordination games without a local interaction 
structure. In their experiments it turned out that preplay communication actually may promote coordination on the payoff-dominant equilibrium. However, their results crucially depend on the kind of communication employed between the players. It would be interesting to see how the experimental design of Cooper et al. would work in our local interaction framework. Third, a serious drawback of most theoretical models of local interaction with respect to economic applications is the assumption of a fixed local interaction structure. Usually, in an economic setting, we expect the agents to build up their own neighborhoods. Few theoretical models exist that examine local interaction structures emerging from evolutionary processes (e.g. Ely, 1995; Dieckmann, 1997). It would be interesting to alter our experimental design by admitting geographical mobility of the players in a population. From the experimental results we hope to obtain valuable information for theoretical modeling. 


\section{References}

Anderlini, L, and A. Ianni, 1993, Path dependence and learning from neighbors. Mimeo, Cambridge University.

Battalio, R., L. Samuelson, and J. van Huyck, 1999, Optimization incentives and coordination failure in laboratory stag hunt games. Mimeo.

Berninghaus, S.K., and K.-M. Ehrhart, 1998, Time horizon and equilibrium selection in tacit coordination games: Experimental results. Journal of Economic Behavior and Organization, 37, 231-248.

Berninghaus, S.K., and U. Schwalbe, 1996, Conventions, local interaction and automata networks. Journal of Evolutionary Economics, 6, 313-324.

Blume, 1.E., 1993, The statistical mechanics of strategic interaction. Games and Economic Behavior, 5, 387-424.

Boyer, R., and A. Orléans, 1992, How do conventions evolve? Journal of Evolutionary Economics, 2, 165-177.

Boylan, R.T., and M.A. El-Gamal, 1992, Fictitious play: A statistical study of multiple economic experiments, Games and Economic Behavior, 5, 205-222.

Bush, R., and F. Mosteller, 1955, Stochastic models for learning. John Wiley \& Sons, New York.

Camerer, C., and T. Ho, 1999, Experience-weighted attraction learning in normal form games. Econometrica, 67, 827-874.

Camerer, C., and M. Knez, 1996, Coordination in organizations: A game theoretic perspective. In: Z. Shapira (ed.), Organizational Decision making. Cambridge Series on Judgement and Decision Making, 158-188.

Cheung, Y.W., and D. Friedman, 1997, Individual learning in normal form games: Some laboratory results. Games and Ecconomic Behavior, 19, 46-76.

Cooper, R., D.V. DeJong, R. Forsythe, and T.W. Ross, 1992a, Forward induction in coordination games. Economics Letters, 40, 167-172.

Cooper, R., D.V. DeJong, R. Forsythe, and T.W. Ross, 1992b, Communication in coordination games. The Quarterly Journal of Economics, 107, 739-773.

Cooper, R., and A. John, 1988, Coordination failures in Keynesian models. Quarterly Journal of Economics, 441-463.

Crawford, V.P., 1991, An "evolutionary" interpretation of Van Huyck, Battalio, and Beil's experimental results on coordination. Games and Economic Behavior, 3, 25-59.

Crawford, V.P., 1995, Adaptive dynamics in coordination games. Econometrica, 63, 103-143. 
Cross, J.G., 1983, A theory of adaptive economic behavior. Cambridge University Press, Cambridge.

Dieckmann, T., 1997, The evolution of conventions with mobile players. Mimeo, National University of Ireland, Maynooth.

Ellison, G., 1993, Learning, local interaction, and coordination. Econometrica, 61, 1047-1071.

Ely, J., 1995, Local conventions. Mimeo, University of California, Berkeley.

Goyal, S., and M. Janssen, 1993, Interaction structure and the stability of conventions.

Mimeo, Erasmus University, Rotterdam.

Harsanyi, J.C., and R. Selten, 1988, A General Theory of Equilibrium Selection in Games. The MIT Press, Cambridge, Massachusetts.

Jones, S.F., 1984, The economics of conformism. Blackwell, Oxford.

Kandori, M., G.J. Mailath, and R. Rob, 1993, Learning, mutation, and long run equilibria in games. Econometrica, 61, 29-56.

Keser, C., K.-M. Ehrhart, and S.K. Berninghaus, 1998, Coordination and local interaction: experimental evidence. Economics Letters, 58, 269-275.

Lewis, D.K., 1969, Convention: A philosophical study. Harvard University Press, Cambridge.

Schelling, T. 1960, The strategy of conflict. Harvard University Press, Cambridge.

Schotter, A., 1981, The economic theory of social institutions. Cambridge University Press, Cambridge.

Siegel, S.S., 1956, Nonparametric statistics for the behavioral sciences. Wiley, New York.

Stahl, D., 1996, Boundedly rational rule learning in a guessing game. Games and Economic Behavior, 16, 303-330.

Sudgen, R., 1986, The evolution of rights, cooperation and welfare. Blackwell, New York.

Van Huyck, J.B., 1997, Emergent conventions in evolutionary games. Mimeo, to appear in: C. R. Plott and V. L. Smith (eds), Handbook of Experimental Economics Results.

Van Huyck, J.B., R.C. Battalio, and R.O. Beil, 1990, Tacit coordination games, strategic uncertainty, and coordination failure. American Economic Review, 80, 234-249.

Van Huyck, J.B., R.C. Battalio, and R.O. Beil, 1993, Asset markets as an equilibrium selection mechanism: Coordination failure, game form auctions, and tacit communication. Games and Economic Behavior, 5, 485-504.

Young, H.P., 1993, The evolution of conventions. Econometrica, 61, 57-84. 


\section{Liste des publications au CIRANO *}

\section{Cahiers CIRANO / CIRANO Papers (ISSN 1198-8169)}

99c-1 Les Expos, l'OSM, les universités, les hôpitaux : Le coût d'un déficit de 400000 emplois au Québec — Expos, Montréal Symphony Orchestra, Universities, Hospitals: The Cost of a 400,000-Job Shortfall in Québec / Marcel Boyer

96c-1 Peut-on créer des emplois en réglementant le temps de travail? / Robert Lacroix

95c-2 Anomalies de marché et sélection des titres au Canada / Richard Guay, Jean-François L'Her et Jean-Marc Suret

95c-1 La réglementation incitative / Marcel Boyer

94c-3 L'importance relative des gouvernements: causes, conséquences et organisations alternative / Claude Montmarquette

94c-2 Commercial Bankruptcy and Financial Reorganization in Canada / Jocelyn Martel

94c-1 Faire ou faire faire : La perspective de l'économie des organisations / Michel Patry

\section{Série Scientifique / Scientific Series (ISSN 1198-8177)}

2000s-35 Strategically Planned Behavior in Public Good Experiments / Claudia Keser

2000s-34 Why Do Experimental Subjects Choose an Equilibrium which Is Neither Payoff Nor Risk Dominant? / Claudia Keser et Bodo Vogt

2000s-33 The Measurement and Antecedents of Turnover Intentions among IT Professionals / Guy Paré et Michel Tremblay

2000s-32 Can the Theory of Incentives Explain Decentralization? / Michel Poitevin

2000s-31 IT Outsourcing Risk Management at British Petroleum / Benoit A. Aubert, Michel Patry, Suzanne Rivard et Heather Smith

2000s-30 A Resource-Based Analysis of IT Outsourcing / Vital Roy et Benoit Aubert

2000s-29 The Impact of Government-Sponsored Training Programs on the Labor Market Transitions of Disadvantaged Men / Lucie Gilbert, Thierry Kamionka et Guy Lacroix

2000s-28 Hope against Hope: Persistent Canadian Unions in the Interwar Years / Michael Huberman et Denise Young

2000s-27 The Impact of Human Resources Practices on IT Personnel Commitment, Citizenship Behaviors and Turnover Intentions / Guy Paré et Michel Tremblay

2000s-26 Organizational and Individual Determinants of Atypical Employment: The Case of Multiple Jobholding and Self-Employment / Gilles Simard, Denis Chênevert et Michel Tremblay

2000s-25 Les déterminants organisationnels et individuels de l'emploi atypique : Le cas du cumul d'emplois et du travail autonome / Gilles Simard, Denis Chênevert et Michel Tremblay

\footnotetext{
* Vous pouvez consulter la liste complète des publications du CIRANO et les publications elles-mêmes sur notre site
} Internet à l'adresse suivante :

http://www.cirano.umontreal.ca/publication/documents.html 